\title{
Gonococcal Tysonitis
}

\author{
K.A.C.R.Wijesekara ${ }^{1}$, N.Abeygunasekara ${ }^{2}$
}

\begin{abstract}
A 31 year old married male presented with urethral discharge, dysuria and painful lump over the penis. Examination revealed thick, yellowish, offensive urethral discharge and tender, enlarged Tyson's gland. Gram staining of the urethral smear showed intracellular and extracellular Gram negative diplococci, suggesting the diagnosis of gonococcal tysonitis. He responded well to the intramuscular ceftriaxone and oral doxycycline therapy.
\end{abstract}

Key words: Gonococcal tysonitis

Authors: corresponding author; ${ }^{1}$ Dr K.A.C.R. Wijesekara, MBBS, PgD Ven, Registrar in Venereology, National STD/AIDS Control Programme, No 29, De Saram Place, Colombo 10, Sri Lanka. Email: randimadr@yahoo.com

${ }^{2}$ Dr N Abeygunasekara, MBBS, PgD Ven, MD; Consultant Venereologist, Teaching Hospital, Kalubowila, Sri Lanka

Conflict of interest: Authors claim no conflicts of interest

Funding: Self financing

Originality: This is an original work and there have not been any previous publications

Submitted: 03.12.2016, Accepted: 15.12 .2016

\section{Full article}

\section{Introduction}

Gonorrhoea is a curable STI with profound impact on sexual and reproductive health. Worldwide annual estimation of new gonococcal infection is 78 million (1). In Sri Lanka during the year 2015, about 450 gonorrhoea cases were reported (2). Usually gonorrhoea resolved without complications. Gonococcal Tysonitis is a very rare complication with only a few reported cases in the world. Literature survey did not reveal any reported cases from Sri Lanka. Following is a case of gonococcal tysonitis.

\section{Case history}

Thirty one year old newly married man attended the STD clinic, Kalubowila complaining of burning pain inside the urethra while passing urine for 1 week, urethral discharge for 5 days and painful lump over the penis for 3 days duration. He had sexual exposures only with marital partner and last sexual exposure was three days back. According to him she was a female sex worker. Examination revealed thick, yellowish discharge with offensive odour at the urethral meatus. There was a soft, tender and erythematous lump $(0.5 \mathrm{~cm} \times 0.5 \mathrm{~cm})$ over the coronary sulcus close to the right side of the frenulum (Figure 1). There was no discharge from the enlarged Tyson's gland. Gram staining of the smear taken from the urethral discharge showed intracellular and extracellular Gram negative diplococci. However, gonococcal culture became negative as there was a delay in transporting the sample to the central lab. Serological tests for syphilis and HIV were negative. The patient was treated with intramuscular ceftriaxone 500mg single dose and doxycycline $100 \mathrm{mg}$ twice daily for seven days. The patient responded well to treatment and intracellular/ extracellular Gram negative

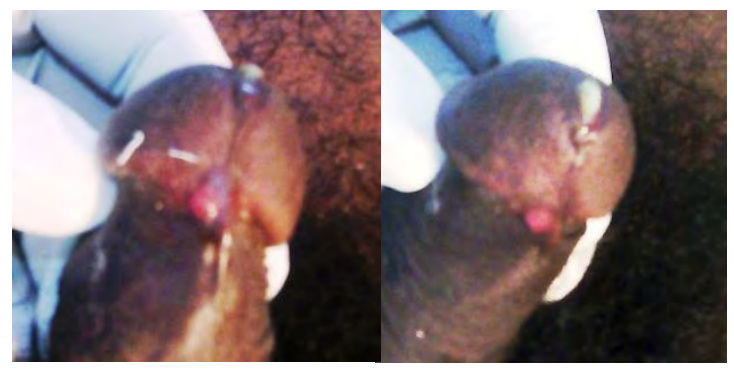


diplococci were absent in the repeated urethral smear.

Figure 1: Purulent urethral discharge with unilateral Tysonitis

\section{Discussion}

This patient was having gonococcal urethritis complicated with unilateral Tysonitis. Tyson's glands are modified sebaceous glands, without hair and with ducts lined by columnar epithelium located one on each side of the frenulum and communicate directly with the prepucial sac. Their function is to produce smegma. Gonococcal Tysonitis is a rare entity causing a protruding cystic globoid enlargement either unilaterally or bilaterally. The cystic swelling is tender and filled with pus (3).

The size of the swelling can vary from a large pea to that of a small olive. There is more chance of infection in patients with congenital genital abnormalities and phimosis. Attention should be paid to such patients with gonorrhoea to rule out Tysonitis.

Tysonitis presents a distinct and unique clinical picture which is easily diagnosed if there is awareness of the condition. Tysonitis can also be caused by other organisms such as Escherichia coli.

Gonococcal urethritis with associated tysonitis is rare. It could be either unilateral as in this patient or bilateral Tysonitis as reported by Fiumara, Subramanian and Abdul Gaffoor in their case reports (4)(5) (6). Bavidge also reported one case of gonococcal tysonitis (7). Tysonitis occur as a local complication of gonorrhoea and it can co-infect with Chlamydia trachomatis in $15-35 \%$ of cases (8). Standard treatment includes $500 \mathrm{mg}$ single dose of intramuscular ceftriaxone with doxycycline $100 \mathrm{mg}$ twice daily for 1 week.

\section{References}

1. World Health Organization. Sexually transmitted and reproductive tract infections. 2016. who.int/reproductivehealth/topics/rtis/en

2. National STD/AIDS Control Programme. Annual report Sri Lanka. 2015.

3. Mc millan, Alexander. Young, Hugh. Ogilvie $M$, Marie. Scott $R$ G. Clinical practice in sexually transmissible infections. 1st edition. Saunders; 2002.

4. Fiumara.N.J. Gonococcal Tysonitis. British Journal of Venereal Diseases. 1977;53:145.

5. Subramanian S. Gonococcal Urethritis with Bilateral Tysonitis and Periurethral Abscess. Sexually Transmitted Diseases. 1981;8:77.

6. Gaffoor PMA. Gonococcal tysonitis. Postgraduate Medical Journal. 1986;62:869-70.

7. Bavidge.K.J.N. Gonococcal infection of the penis. British Journal of Venereal Diseases. 1976;52:66.

8. National STD/AIDS Control Programme. Sexually transmitted infections management guideline Sri Lanka. 2009. 